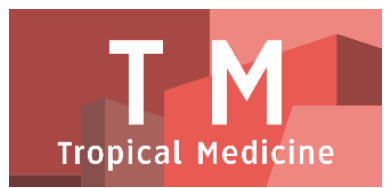

PAPER - OPEN ACCESS

\title{
Pengalaman Hidup Pada Pasien Dengan End Colostomy di Kota Medan
}

Author : Miftahul Handayani Lubis

DOI $\quad: 10.32734 / \mathrm{tm} . \mathrm{v} 1 \mathrm{i} 1.59$

Paper Page : $47-52$

Volume 1 Issue 1 - 2018 TALENTA Conference Series: Tropical Medicine (TM)

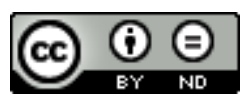

This work is licensed under a Creative Commons Attribution-NoDerivatives 4.0 International License.

Published under licence by TALENTA Publisher, Universitas Sumatera Utara
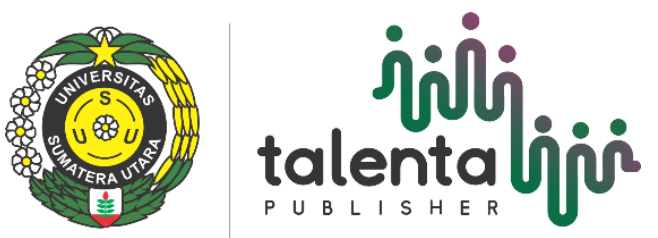


\title{
inili talentalịio TALENTA Conference Series \\ P U B L I S H E R Available online at https://talentaconfseries.usu.ac.id \\ Pengalaman Hidup Pada Pasien Dengan End Colostomy di Kota Medan
}

\author{
Miftahul Handayani Lubis, ${ }^{\mathrm{a}, *}$, Yesi Ariani \\ ${ }^{a}$ Fakultas Keperawatan, Universitas Sumatera Utara, Medan 20155, Indonesia \\ bmpslice@gmail.com, yesiariani@yahoo.com
}

\begin{abstract}
Abstrak
Angka kejadian kolostomi meningkat dari tahun ke tahun, tindakan kolostomi paling sering dilakukan karena adanya karsinoma kolon dan rectum. Indonesian Ostomy Association (InOA) mengatakan bahwa jumlah kasus yang menggunakan stoma terus meningkat, dan penyebab tersering di Indonesia sendiri adalah karena keganasan. Penelitian ini menggunakan desain kualitatif dengan fenomenologi deskriptif yang memiliki tujuan untuk menjelaskan fenomena, penampilan dari sesuatu yang khusus. Tujuan penelitian ini ntuk mengetahui pengalaman hidup pada pasien dengan end colostomy di kota Medan.Pemilihan partisipan menggunakan metode purposive sampling. Pengambilan data dilakukan di beberapa Rumah Sakit di Kota Medan, tetapi penelitiannya dilakukan di rumah pasien. dengan kriteria partisipan komunikatif. partisipan berjumlah sepuluh partisipan. Pengumpulan data dimulai dari bulan Februari 2016 sampai dengan bulan April 2016. Berdasarkan hasil wawancara mendalam yang dilakukan terhadap sepuluh partisipan, maka penelitian ini menemukan ada 4 tema terkait pengalaman hidup pada pasien dengan end colostomy di kota medan, yaitu : (1) perawatan end colostomy (2) menderita secara psikologis (3) menderita secara fisik (4) pembuatan kantong stoma. Diharapkan bagi pelayanan keperawatan untuk memberikan informasi yang jelas mengenai 10 hak ostomate agar pasien dapat lebih memahami hak-hak mereka sebagai pasien end colostomy. Disarankan bagi peneliti selanjutnya untuk dapat melakukan penelitian yang lebih mendalam mengenai pengalaman pasien kolostomi..
\end{abstract}

Kata Kunci: Pengalaman Hidup Pasien; End Colostomy

\section{Pendahuluan}

Indonesian Ostomy Association (InOA) mengatakan bahwa jumlah kasus yang menggunakan stoma terus meningkat, dan penyebab tersering di Indonesia sendiri adalah karena keganasan [8]. Perawatan stoma harus diajarkan pada pasien dan keluarga. Singkatnya masa perawatan (2-4 minggu) membuat pasien belum dapat sepenuhnya terlatih dalam teknik perawatan stoma sebelum pulang [10]. Pemasangan stoma ini ada yang bersifat sementara dan ada yang menetapkan untuk seumur hidup. Bagi yang harus dipasang untuk seumur hidup, kemungkinan besar akan berdampak pada aspek-aspek kehidupan dari pasien tersebut baik fisik, psikologis, sosial, dan spiritual. Dengan kata lain, hal tersebut juga akan berdampak pada kepuasan, kebahagiaan, dan pengalaman pasien [20].

Untuk mengantisipsi luka stoma agar tidak terjadi infeksi maka akan dilakukannya perawatan kolostomi. Kolostomi adalah pembuatan lubang sementara atau permanen dari usus besar melalui dinding perut dengan tindakan bedah bila jalan ke anus tidak bisa berfungsi, dengan cara pengalihan aliran feses dari kolon karena gangguan fungsi anus [20] Mayers pada [16] menyebutkan bahwa alasan paling sering dilakukannya tindakan kolostomi adalah adanya karsinoma pada kolon dan rectum dimana karsinoma adalah tumor ganas yang tumbuh dari jaringan epitel. Lubang kolostomi yang muncul dipermukaan abdomen berupa mukosa kemerahan yang disebut 
stoma. Penyebab terbanyak dari indikasi pembuatan kolostomi adalah karena kanker atau keganasan. Kebanyakan dapat dicegah dengan cara menjaga gaya hidup sehat masyarakat perkotaan, yaitu menjaga pola makan sehat dan berat badan ideal, melakukan olahraga secara rutin, teratur dan terukur, serta mengurangi asupan alcohol [1].

\section{Metode Penelitian}

Penelitian ini menggunakan desain fenomenologi deskriptif. Pemilihan partisipan dalam penelitian ini menggunakan metode purposive sampling yaitu metode pemilihan partisipan dalam suatu penelitian dengan menentukan terlebih dahulu kriteria yang akan dimasukkan dalam penelitian [12].

Pengumpulan data dilakukan setelah mendapat izin dari Dekan Fakultas Keperawatan Universitas Sumatera Utara dan memperoleh ethical clearance. Selanjutnya peneliti meminta izin dari rumah sakit untuk mengambil data pasien stoma melalui rekam medik dari RSUP Haji Adam Malik Medan untuk memperoleh data calon partisipan sesuai dengan kriteria yang ditentukan. Setelah mendapatkan data partisipan yang dibutuhkan maka peneliti langsung meenguhubungi partisipan untuk menanyakan apakah partisipan menyetujui untuk dilakukannya wawancara. Setelah partisipan menyetujui lalu peneliti melakukan kontrak waktu untuk melakukan wawancara. Selanjutnya peneliti melakukan Pilot study. Pilot study atau uji coba instrumen penelitian dilakukan pada pengumpulan partisipan pertama. Maksudnya untuk mengetahui apakah instrument tersebut cukup handal atau tidak, komunikatif, dapat dipahami, dan sebagainya.Pilot study dilakukan dengan cara mewawancarai seorang partisipan dam membuat transkip serta dibuat hingga analisa data dan diskusi kepada pembimbing untuk melihat hasil dari pilot study tersebut. Setelah mendapatkan persetujuan pembimbing, kemudian peneliti melanjutkan wawancara kepada partisipan berikutnya

\section{Hasil Penelitian}

Hasil penelitian ini mendapatkan 4 tema terkait pengalaman hidup pada pasien dengan stoma kolostomi di kota medan. Keempat tema tersebut meliputi (1) perawatan end colostomy (2) menderita secara psikologis (3) menderita secara fisik (4) pembuatan kantong stoma

\subsection{Perawatan End Colostomy}

Partisipan dalam penelitian ini mengatakan bahwa melakukan pengobatan dari pelayanan kesehatan karena mereka percaya akan pengobatan yang dilakukan oleh tim medis hal ini dilakukan oleh pasien karena penyakit yang dialami oleh partisipan adalah penyakit medis yang seharusnya di bawa ke pelayanan kesehatan. Berikut pernyataan partisipan:

“...Insyallah gak ada sama sekali karna saya yakin obat yang di kasih sama dokter itu udah cukup bagus untuk kesehatan saya...” (Partisipan 2)

Partisipan mengatakan bahwa membersihkan keseluruhan area end colostomy menggunakan air, sabun dan tisu hingga end colostomi bersih. Berikut pernyataan partisipan:

"Cemanalah pula dibilang ya, gak ada kesulitan lah, biasa aja kakek rasa kalau membersihkannya ya kakek bersihkan biasalah ala kadarnya aja paling pake air terus kakek keringkan udah kayak gitu ajalah kakek buat" (Partisipan 1)

Pasien end colostomy mengatakan konsistensi feses tergantung makanan yang dimakan. Berikut pernyataan partisipan:

“...Apa yang aku makan gak tentu dek jadi mau dia mencret mau dia agak lembek...” (Partisipan 3) 
Pasien end colostomy mengkonsumsi makanan lunak dan tidak pedas. Hal ini sejalan dengan partisipan:

“...Makan ya kayak biasa jamnya tapi yang dimakan nasinya agak lembek dibuat pake lauk pauknya kalau bisa jangan makan yang pedas kali nanti mencret buatnya...” (Partisipan 7)

Partisipan mendapatkan bantuan dari keluarga dalam membersihkan end colostomy. Hal ini di sesuai dengan pernyataan partisipan.

“...Siapalah paling nenekmu lah yang rawat bantu sikit itupun kalau kakek gak bisa sendiri tapi selama bisa sendiri mana mau kakek minta bantuan sama nenekmu...” (Partisipan 1)

\subsection{Menderita Secara Psikologis}

Pasien dengan end colostomy mengatakan cemas saat di pasang end colostomy dan cemas karena biaya. Berikut pernyataan partisipan.

“...Rasanya ya apalah, apa namanya ada juga cemas pas dipasang kolostomi pas dipasang kolostomi...” (Partisipan 1)

Pasien mengatakan sedih karena dipasang end colostomy. Berikut pernyataan partisipan:

“...Sedihlah awalnya malu sama tetangga, pasti di omongin tetangga entah apa-apa, belum lagi nanti bakalan gak bisa apa-apa kakek...” (Partisipan 1)

Pasien mengatakan pasrah akan kondisi penyakit sebagai ujian dari Allah SWT, hal ini sejalan dengan pernyataan partisipan:

“...Perasaan gitu ya cemana lah perasaan dibilang gitu pasrah ajalah gitu ya menerima aja gimana ya kan sementara penyakit yang dirasakan itu sebenarnya udah tahu bahwasanya ada tumor..." (Partisipan 4)

\subsection{Menderita secara Fisik}

Pasien mengatakan sakit, gatal dan merasa bengkak pada area end colostomy. Berikut pernyataan partisipan:

“...Kalau gatal gatal ada tapi kalau dia merah atau apa gak tau kakek karna gak pernah kakek perhatikan kali..." (Partisipan 1)

Partisipan mengatakan adanya kemerahan pada area end colostomy. Berikut pernyataan partisipan:

“...Ada juga lah kadang kalau udah sering kali dibersihkan merah merah dia tapi merahnya beda dia numpuk gitu merahnya di satu tempat...” (Partisipan 5)

\subsection{Pembuatan Kantong Stoma}

Partisipan membuat kantong end colostomy sendiri untuk melakukan penghematan. Berikut pernyataan partisipan:

“...Sekarang udah aku bikin sendiri karena gak sangguplah beli terus karna saya permanen kan...” 


\section{Pembahasan}

Bagian ini akan diuraikan tentang pembahasan hasil penelitian dengan konsep atau teori yang ada, perbandingan dengan hasil penelitian yang pernah dilakukan sebelumnya berhubungan dengan pengalaman hidup pada pasien dengan end colostomy di kota medan.

Pasien stoma memiliki faktor resiko yang sangat tinggi untuk terkena infeksi akibat pengobatan yang tidak sesuai, oleh sebab itu sangat dianjurkan bagi pasien untuk melakukan pengobatan di pelayanan kesehatan agar perawat dapat menangani stoma sampai pasien dapat mengambil alih perawatan ini. Pada proses perawatan kulit di pelayanan kesehatan harus diajarkan bagaimana menerapkan drainase kantung dan melaksanakan irigasi kantong stoma [4]. Pendapat tersebut sesuai dengan pernyataan partisipan bahwa, partisipan tetap melakukan pengobatan di pelayanan kesehatan, karena mereka percaya bahwa pengobatan harus dilakukan oleh tim medis karena penyakit yang dialami oleh partisipan merupakan penyakit medis yang seharusnya di tangani oleh tim medis di pelayanan kesehatan.

Partisipan dalam penelitian ini membersihkan end colostomy dengan menggunakan air dan mengganti kantong stoma secara rutin. Sebahagian partisipan melakukan penggantian kantong stoma setiap buang air besar. Hal tersebut sesuai dengan hasil penelitian Truven Health Anaytics [20] bahwa penggantian kantong stoma harus disertai dengan membersihkan stoma. Stoma cukup dibersihkan dengan air dan hindari penggunaan sabun karena dapat mengiritasi.

Pasien dengan stoma tidak dapat mengontrol pengeluaran feses dan flatus, oleh karena itu edukasi terkait nutrisi perlu diberikan kepada pasien agar terhindar dari gangguan odor ataupun konsistensi feses yang tidak normal [7] Hal tersebut sesuai dengan pernyataan partisipan bahwa sesuai dengan pengalaman mereka bahwa konsistensi feses yang keluar tidak dapat dipastikan dan semua tergantung pada makanan yang di konsumsi oleh partisipan itu sendiri. Oleh sebab itu partisipan tetap mengkonsumsi makanan yang sesuai untuk mengontrol feses mereka.

Pasien membutuhkan orang lain dalam proses perawatan end colostomy setelah meninggalkan rumah sakit. Diharapkan keluarga dapat terlibat dalam perawatan stoma pasien, sehingga keluarga nantinya dapat memantau dan membantu pasien [23]. Seperti yang disampaikan oleh beberapa partisipan bahwa mereka membutuhkan pertolongan atau bantuan dari keluarga terdekat dalam hal membersihkan end colostomy. Bantuan yang diberikan oleh keluarga merupakan pertolongan dasar yang tidak mampu dilakukan sendiri oleh partisipan seperti menyiapkan perlengkapan untuk membersihkan end colostomy.

Pasien yang dipasang untuk seumur hidup, kemungkinan besar akan berdampak pada aspek-aspek kehidupan dari pasien tersebut baik fisik, psikologis, sosial, dan spiritual. Dengan kata lain, hal tersebut juga akan berdampak pada kepuasan, kebahagiaan, dan pengalaman pasien [21]. Seperti analisa data yang didapat dari penelitian ini bahwa partisipan mengalami masalah fisik dan psikologis.

Masalah psikologis yang dialami oleh seorang pasien stoma merupakan salah satu penghalang bagi pasien tersebut untuk dapat hidup produktif. Hal tersebut disebabkan oleh kecemasan dan merasa malu memiliki stoma yang dapat menyebabkan perubahan pada gaya hidup, termasuk kemampuan untuk mencari pekerjaan, keinginan untuk melakukan perjalanan, dan penilaian terhadap citra tubuhnya [16]. Sama halnya pada penelitian ini ditemukan bahwa partisipan merasakan cemas serta malu terhadap lingkungan karena menggunakan end colostomy di awal pemasangan. Partisipan mencemaskan keterbatasan fisik yang akan dialaminya setelah penggunaan end colostomy. Partisipan merasa pemasangan end colostomyakan membatasi ruang gerak fisiknya karena partisipan harus membawa kantong end colostomy kemanapun ia pergi sebab partisipan harus segera mengganti kantong end colostomy setelah buang air besar. Terlambatnya penggantian kantong end colostomyakan menimbulkan aroma yang kurang sedap dari kotoran pada kantong end colostomy, hal ini lah yang membuat partisipan selalu merasa cemas dan malu saat berinteraksi dengan lingkungannya. Namun rasa cemas dan malu tersebut hanya dirasakan oleh partisipan pada awal pemasangan kantong end colostomy saja karena setelah terbiasa partisipan akan lebih cepat dan tanggap untuk mengganti kantong end colostomy.

Pada penelitian ini diketahui bahwa daerah stoma mengalami iritasi dengan tanda dan gejala kemerahan, gatal dan bengkak setelah partisipan melakukan pembersihan di sekitar end colostomy, hal tersebut wajar dialami oleh pasien end colostomy. Namun beberapa partisipan mengatakan bahwa masalah fisik yang dialami oleh partisipan tidak hanya hal tersebut, rasa sakit yang bersumber dari area end colostomy terasa menjalar keseluruh bagian tubuh khususnya daerah pinggang sampai ke punggung partisipan. Seperti halnya yang disebutkan pada penelitian [10] 
dari 325 responden, 73\% melaporkan adanya masalah dermatosis termasuk reaksi iritasi pada kulit setelah menggunakan kantong end colostomy yang normal. Dari analisa data pada penelitian tersebut ditemukan juga gangguan fisik berupa rasa sakit, gatal dan bengkak pada area end colostomy juga kemerahan pada daerah end colostomy.

Partisipan dalam penelitian ini menyampaikan bahwa upaya penghematan dalam pengeluaran untuk biaya perawatan dapat dilakukan dengan membuat sendiri kantong stoma dengan menggunakan plastic gula berukuran $1 / 2$ $\mathrm{kg}$ atau $1 \mathrm{~kg}$ yang dilubangi sesuai dengan ukuran stoma partisipan dan menggunakan double tipe sebagai perekat kantong stoma. Hal tersebut sesuai dengan pendapat dari setryoni, [18] yang menyatakan bahwa bagi pasien yang tidak mampu, kantong stomanya dapat dimodifikasi / dipilihkan dengan cara menggunakan kantong plastik gula yang ditempel menggunakan double tape atau bisa juga plastik tersebut hanya dilubangi sesuai lebarnya diameter stoma pada salah satu sisi bagian tengah atas, kemudian bagian sisi kiri \& kanannya diberi tali untuk ikat pinggang.

\section{Kesimpulan}

Berdasarkan hasil wawancara mendalam yang dilakukan terhadap sepuluh partisipan, maka penelitian ini menemukan ada 4 tema terkait pengalaman hidup pada pasien dengan end colostomy di kota medan, yaitu: perawatan end colostomy (2)menderita secara psikologis (3) menderita secara fisik pembuatan kantong stoma.

\section{Referensi}

[1] Anna, L. K. (2011) "Dunia masih perang kanker”. 16 Juni 2013. http://health.kompas.com/read/2011/02/04/09424894/Dunia.Masih.Perang.Melawan.Kanker.

[2] Black, P. (2004) "Psychological, sexual and cultural issues for patients with a stoma". British Journal of Nursing. 13(12), 692-697.

[3] Burch, J. (2013) "Care of patients with a stoma”. Nursing Standart: 27 (32) :49-56. http://search.proquest.com/docview/1346256?accountid=25704

[4] Brunner \& Suddarth"s. (2004) "Textbook of Medical Surgical Nursing”. Canada Care Medical. (n.d). Colostomy care. 20 Mei 2013. http://www.canadacaremedical.com/ostomy/colostomycare.php

[5] Eucomed Medical Technology. (2012) "Access to ostomy supplies and innovation: Guiding principles for european payers". 28 Juni 2013. http://www.medtecheurope.org/uploads/modules/publications/ostomy-background-paper.pdf

[6] Fatwa Majelis Ulama Indonesia. (2009). Jakarta. 25 agustus 2009. http://www.mui.or.id/

[7] Gutman, N. (2011). Colostomy guide. 20 Mei 2013. http://www.ostomy.org/ostomy_info/pubs/ColostomyGuide.pdf

[8] Indonesian Ostomy Association. (2009). Informasi organisasi indonesian ostomy association. 27 Juni 2013.

[9] Kurnia, D. A. (2012) "Kolostomi, manajemen dan kualitas hidup untuk pasien”. 27 Juni 2013. http://kesehatan.kompasiana.com/medis/2012/12/21/kolostomi-manajemen-dan-kualitas-hidupuntuk-pasien-512846.html

[10]Lyon, C. C., Smith, A. J., Griffith, C. E., and Beck, M. H. (2000) "The spectrum of skin disorders in abdominal stoma patients.” The British Journal of Dermatology [Br J Dermatol], ISSN: 00070963, 2000 Dec; vol.143 (6), pp. 1248-60; PMID:11122029.

[11] Nuari, N. A. (2015) “Asuhan keperawatan pada gangguan sistem gastroinestinal”. Jakarta : CV. Trans Info Media.

[12]Piccinellil, M., Brazzale, R. and Saracco, C. (2009) "Assessment of the grevalence and perception of skin problems in patients with permanent stoma”. Journal Article Country of Publication: Nursing, 2009 Oct-Dec; vol. 28(4), pp.183-9; PMID:20222519.

[13]Polit, D. F. \& Beck, C. T. (2012) "Nursing research: Generating and assesing evidence for nursing practice (9thed)". Philadelphia: Lippincott.

[14]Potter, P. A \& Perry, A. G. (2005) “Buku ajar fundamental keperawatan. konsep, proses dan praktik. Edisi 4. Volume 2”. Jakarta: EGC.

[15]Putri, R. H. (2011). Irigasi Kolostomi. 25 Juni 2013. http://www.perawatluka.com/irigasi-kolostomi/.

[16] Pratiwi, Y. (2014) "Gambaran konsep diri pada klien dewasa muda dengan kolostomi permanen di yayasan kanker Indonesia Jakarta pusat". http://www.yunisapratiwi.pdf

[17] Simanjuntak, P. \& Nurhidayah, R. E. (2007) "Kemampuan self sare dan gambaran diri pasien kolostomi di RSUP H. Adam Malik Medan". Jurnal Keperawatan Rufaidah Sumatera Utara: 2(2). 65-69.

[18] Setyorini, D. (2007) "Pemilihan kantong stoma yang tepat bagi ostomate". http://www.pemilihan_kantong_stoma.pdf

[19] Smeltzer \& Bare. (2002) "Buku ajar keperawatan medical bedah”. (Penerjemah: Waluyo, A.). Jakarta : EGC

[20] Sodikin. (2011) “Asuhan Keperawatan anak: Gangguan sistem gastrointestinal dan hepatobilier”. Jakarta: Salemba Medika.

[21] Suratun \& Lusiana. (2010) “Asuhan keperawatan klien gangguan sistem gastrointestinal”. Jakarta: CV. Trans Info Media.

[22] Truven Health Analytics. (2012). Colostomy care. 20 Mei 2013. http://www.drugs.com/org/colostomycare.html

[23] WHO. (2005). Pedoman perawatan pasien. Jakarta: EGC. WHO. (2008). Colorectal cancer incidence, mortality and prevalence worldwide in 2008. Diperoleh dari: http://globocan.iare.fr/. Diakses pada 30 Oktober 2012 
[24] WOCN Society. (2008). Basic ostomy skin care. 20 Mei 2013. http://www.ostomy.org/ostomyinfo/wocn/wocnbasicostomyskincare.pdf 